\title{
Facilitation of drug resistance development by $\gamma$-irradiation in human cancer cells
}

\author{
TSUN YEE TSANG, SZE WING TSANG, KA PO LAI, WING PUI TSANG, NGAI NA CO and TIM TAK KWOK \\ Department of Biochemistry, The Chinese University of Hong Kong, Shatin, Hong Kong SAR, P.R. China
}

Received February 18, 2009; Accepted May 12, 2009

DOI: $10.3892 /$ or_00000518

\begin{abstract}
Hepatocellular carcinoma HepG2 cells ( $\mathrm{G}$ cells) were subjected to selection first with $\gamma$-radiation and then doxorubicin (Dox). The radiation treatment consisted of 2 Gy for 10 days $(\mathrm{G} 2)$ or 10 Gy for 2 days $(\mathrm{G} 10)$ and the Dox treatment was continuous exposure for up to $10 \mu \mathrm{M}$. Compared with respective parental G, G2, G10 cells, the Doxselected cells showed $m d r l$ amplification/P-glycoprotein overexpression, Dox resistance and also less intracellular Dox accumulation. Verapamil reversed the drug resistance and increased the Dox accumulation in all cells. Decay in drug resistance and reduction in $m d r l$ amplification/P-glycoprotein overexpression were observed in the Dox-selected cells culturing in Dox-free condition. Among the Dox-selected cells, G2R cells showed the highest levels of drug resistance, $m d r l$ amplification, but the least resistance decay. Results from the study indicate the possible influence of radiation treatment on the development of drug resistance in cancer cells and it may even lead to a highly resistant phenotype.
\end{abstract}

\section{Introduction}

Multidrug resistance (MDR) is one of the major obstacles in cancer therapy (1). It is a phenomenon where cancer cells that have been exposed to a single anticancer drug may develop cross-resistance to a range of structurally and functionally unrelated drugs. Increase in drug efflux is one of the major mechanisms that leads to MDR in cancer cells (2).

P-glycoprotein (Pgp), the product of the human $m d r l$ gene, is a $170 \mathrm{kDa}$ membrane transporter that acts as a drug efflux pump. Pgp belongs to the ATP-binding cassette (ABC) protein family and it effluxes neutral and cationic hydrophobic compounds by hydrolyzing ATP (3). However, Pgp can also transport a large panel of anticancer drugs, including anthracycline (doxorubicin and daunorubicin), the microtubule-

Correspondence to: Dr Tim Tak Kwok, Department of Biochemistry, Science Centre, The Chinese University of Hong Kong, Shatin, Hong Kong SAR, P.R. China

E-mail: kwok2020@chuk.edu.hk

Key words: multidrug resistance, P-glycoprotein, radiotherapy, chemotherapy, doxorubicin stabilizing drug Taxol and vinca alkaloids (vinblastine and vincristine) (4). Because of its ability in effluxing drugs, Pgp can lower the intracellular concentration of drugs and thus leads to MDR of cancer cells. The Pgp expression level is found to be correlated with the level of drug resistance in cancer. Transfection with $m d r l$ gene into the drug-sensitive cells can induce MDR phenomenon in cells (5). Inhibitor of Pgp, such as verapamil, the calcium channel blocker, which can block Pgp from effluxing drugs, was found to increase the drug sensitivity of cancer cells (6).

Induction of $m d r l$ expression has been reported in cancer cells after prolonged treatment with anticancer drugs. This phenomenon may account for the acquired drug resistance in cancer cells during the course of chemotherapy. The anticancer drugs that lead to this phenomenon are commonly used in clinical treatment, including doxorubicin (Dox) (7), Taxol (8) and vincristine (9). In addition, Pgp induction can be found in cells after irradiation treatment. In vitro exposure of tumor cells to fractionated irradiation (10) or to single dose of X-ray irradiation (11) can lead to increase in the expression level of Pgp.

In clinical practice, the treatment for cancer patients are usually involved the combination of radiotherapy with chemotherapy. In the in vitro studies, co-treatment with radiation and anticancer drugs may have additive (12) or synergic effect (13) in cancer treatment. However, there is scarce information on the long-term impact, in particular, the development of drug resistance in cancer cells after cotreatment with radiotherapy and chemotherapy. Therefore, we studied the drug resistance profile developed in human hepatocellular carcinoma HepG2 cells that survived after treatment with radiation followed by an anticancer drug. In comparison with those treated with anticancer drug alone, the cells with radiation treatment before the drug treatment may show a higher and more stable $m d r l$-associated drug resistance.

\section{Materials and methods}

Cell culture. The cell lines were established from human hepatocellular carcinoma HepG2 cells (G cells). G cells were first subjected to radiation selection by two different regimes and the two radiation-conditioned sublines are the $\mathrm{G} 2$ and G10 cells; G2 cells are cells surviving after 10 days of 2 Gy radiation treatment while G10 cells survived after 2 days of 10 Gy radiation treatment. G, G2 and G10 cells were then incubated with increasing concentration of Dox for up to $10 \mu \mathrm{M}$ and the three drug-selected sublines are the GR, G2R 


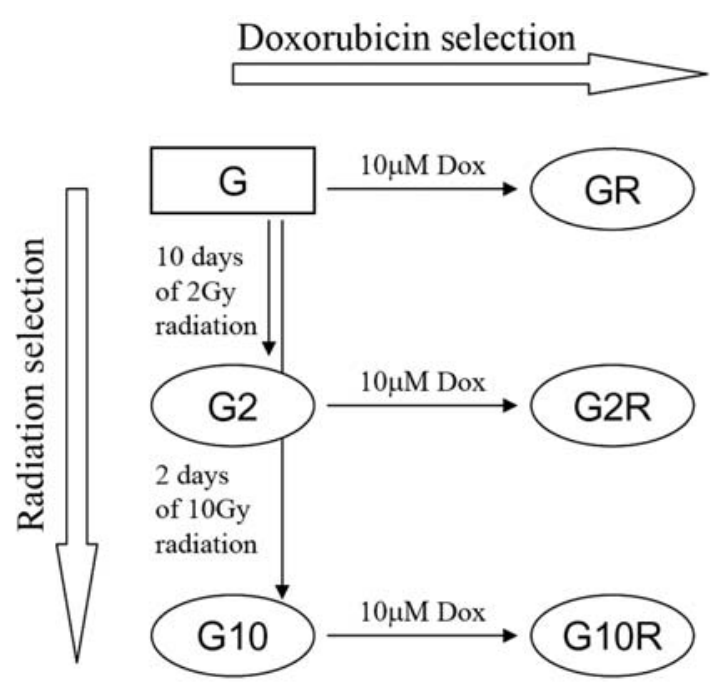

Figure 1. The establishment of radiation and Dox-selected HepG2 cells. HepG2 cells ( $\mathrm{G}$ cells) were first subjected to radiation selection by two different regimes and the two radiation-conditioned sublines G2 and G10 cells; G2 cells survived after 10 days of 2 Gy radiation treatment while G10 cells survived after 2 days of 10 Gy radiation treatment. G, G2 and G10 cells were then incubated with increasing concentration of Dox for up to $10 \mu \mathrm{M}$ and the three drug-selected sublines GR, G2R and G10R cells, which are the G, G2 and G10 cells survived after Dox treatment, respectively.

and G10R cells, which are the G, G2 and G10 cells survived after Dox treatment, respectively (Fig. 1). G, G2 and G10 cells were cultured in Dulbecco's modified essential medium (DMEM) supplemented with $5 \%$ fetal bovine serum (Invitrogen, USA) and L-glutamine (Invitrogen) at $37^{\circ} \mathrm{C}$ in a humidified atmosphere with $10 \% \mathrm{CO}_{2}$. The Dox-selected sublines, GR, G2R and G10R cells, were cultured at the same condition except that the DMEM contained 1.2 $\mu \mathrm{M}$ Dox.

MTT cell viability assay. Cells were plated onto 96-well plates and then treated with anticancer drugs, including Dox, Taxol, vincristine, etoposide, methotrexate (Sigma, USA) and tamoxifen (CalBiochem, USA). After 5 days of drug treatment, the cells were incubated with $50 \mu 1$ of $0.1 \mathrm{mg} / \mathrm{ml}$ 3-(4,5-Dimethylthiazole-2-yle) -2,5-diphenyltetrazolium bromide solution (USB, USA) at $37^{\circ} \mathrm{C}$ for $3 \mathrm{~h}$ and then lysed in $150 \mu \mathrm{l}$ of dimethyl sulfoxide at room temperature for $30 \mathrm{~min}$. The absorbance of each well was measured at $570 \mathrm{~nm}$ in a microplate reader.

Dox accumulation assay. Cells were treated with 2 or $4 \mu \mathrm{M}$ of Dox for $5 \mathrm{~h}$. After that, the cells were trypsinized and subjected to flow cytometric analysis using BD FACSort flow cytometer (Becton-Dickinson, USA). The intensity for fluorescence from Dox in cells was measured. To investigate the Pgp role in Dox accumulation, an inhibitor, verapamil (Sigma) was used. Cells were treated with $50 \mu \mathrm{M}$ verapamil together with $2 \mu \mathrm{M}$ Dox for $5 \mathrm{~h}$ before the flow cytometry assay.

Western blot analysis. Cells were lysed in lysis solution containing 1\% Triton $\mathrm{X}-100$. Protein from each sample was separated by SDS-PAGE and transferred onto PVDF membrane (Millipore, USA) by electro-blotting. The
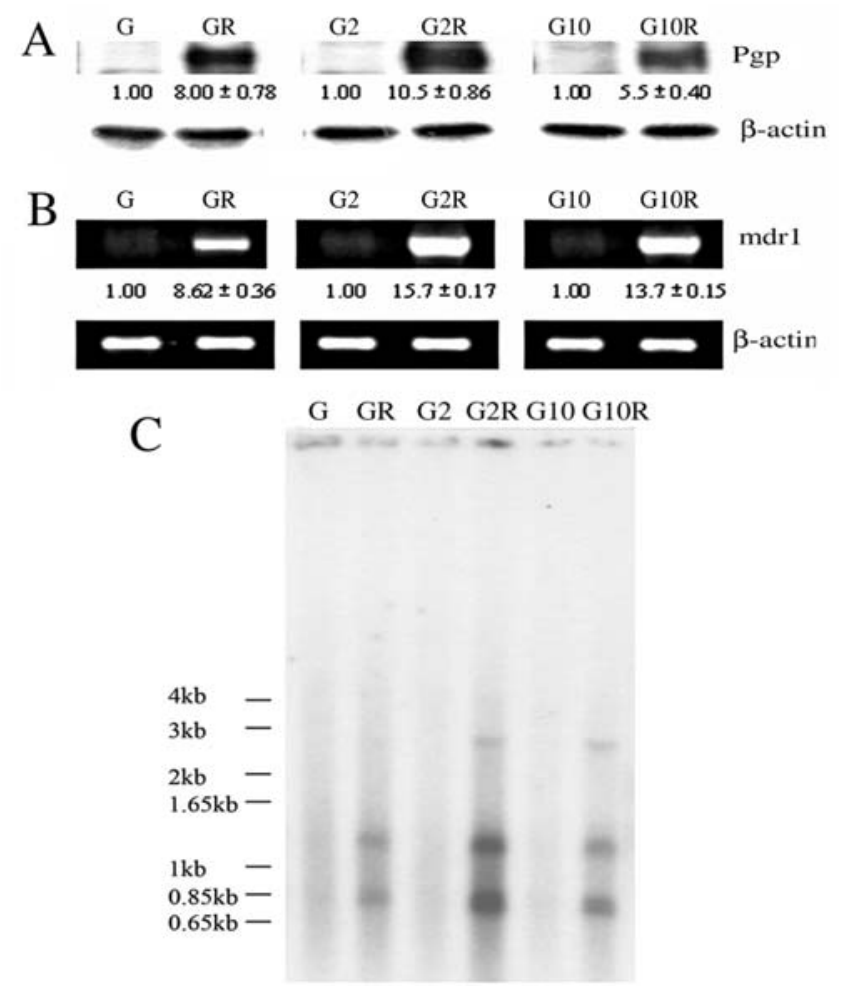

Figure 2. The expression level of $m d r 1$ in HepG2 cells and its sublines. (A) The Pgp level in cells was determined by Western blot analysis. (B) The $m d r 1$ mRNA level was determined by RT-PCR. The experiments were repeated at least 3 times with similar results, and one representative is shown. The expression level of Pgp or $m d r l$ mRNA in each sample was normalized with the level of $B$-actin. The relative Pgp or $m d r 1$ mRNA expression level of the Dox-selected cells was calculated in relation to that of the respective parental cells. (C) Southern blot analysis of $m d r 1$ gene in HepG2 cells. The experiments were repeated at least 3 times with similar results, and a representative one is shown.

membrane was incubated with primary antibody for $2 \mathrm{~h}$ and with respective horseradish peroxidase-conjugated secondary antibody for $1 \mathrm{~h}$. The primary antibodies are antiP-glycoprotein (Oncogene, USA) and B-actin (Sigma). The protein bands were detected by the ECL Western blotting detection reagent (Amersham Pharmacia, USA). The protein band intensity was scanned and analyzed by ImageJ (version $1.38 \mathrm{x})$ software (14).

$R T$-PCR. Cells were lysed by Tri Reagent (Molecular Research Center, USA) for RNA extraction. After that, total RNA was subjected to reverse transcription with oligo dT primer (Invitrogen) by MMLV Reverse Transcriptase (Promega, USA). PCR amplification using the pair of primers specific to $m d r l$ within its open reading frame was carried out for 30 cycles of $94^{\circ} \mathrm{C}$ for $30 \mathrm{sec}, 55^{\circ} \mathrm{C}$ for $1 \mathrm{~min}$ and $72^{\circ} \mathrm{C}$ for $1 \mathrm{~min} 30 \mathrm{sec}$; forward primer (5'-GATCTTGAAGGGGA CCGCAATGGA-3') and reverse primer (5'-GATGCATAG ATCAGCAGGAAAGCAGC-3'). RT-PCR assay with primers specific for $B$-actin was also performed.

Southern blot analysis. Cells were lysed in lysis buffer containing $100 \mathrm{mM} \mathrm{NaCl}, 10 \mathrm{mM}$ Tris-Cl, $25 \mathrm{mM}$ EDTA, $0.5 \% \mathrm{SDS}$ and $0.1 \mathrm{mg} / \mathrm{ml}$ Protease $\mathrm{K}$. After incubation at $50^{\circ} \mathrm{C}$ for $18 \mathrm{~h}$, the genomic DNA was extracted by phenol- 

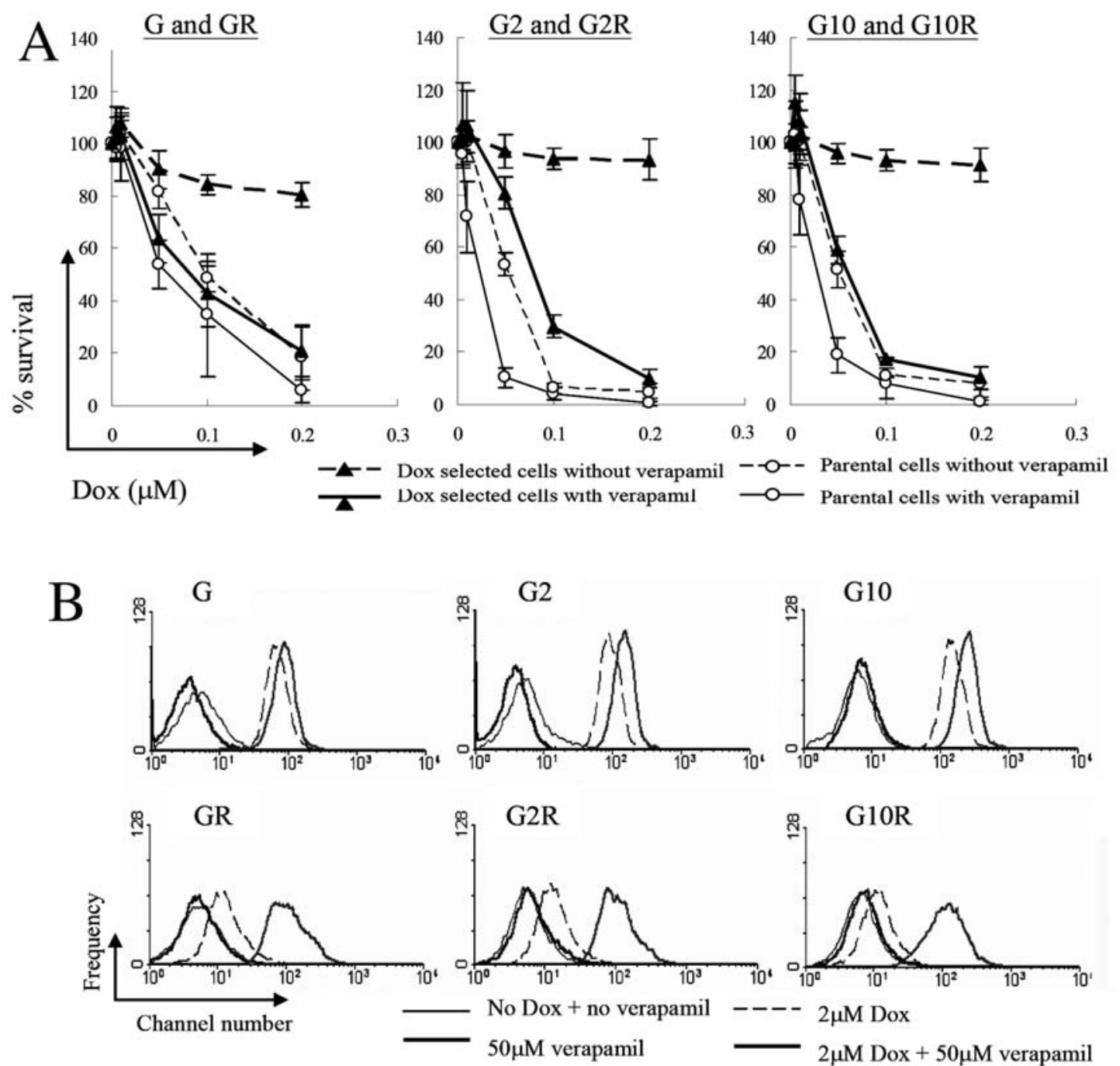

Figure 3. The effect of verapamil on Dox sensitivity and accumulation in HepG2 cells. (A) The cells were treated with Dox together with $30 \mu \mathrm{M}$ verapamil. MTT assay was performed after 5 days of drug incubation and the percentage of cell survival was calculated. ( $\mathbf{\Delta})$ Represents the Dox-selected cells and ( $\odot$ ) represents the respective parental cells. (Continuous line) represents cells treated with $30 \mu \mathrm{M}$ verapamil while (dashed line) represents cells without verapamil treatment. Each data point was average of results obtained from at least three separate experiments. Error bar, standard deviation. (B) The cells were treated with $2 \mu \mathrm{M}$ Dox together with $50 \mu \mathrm{M}$ verapamil. After $5 \mathrm{~h}$ incubation, the level of Dox accumulated inside the cells was determined by flow cytometry. (Continuous line) represents the cells with no drug treatment. (Dashed line) represents the cells treated with $2 \mu \mathrm{M}$ Dox. (Thick bold line) represents the cell treated with $50 \mu \mathrm{M}$ verapamil. (Thick grey line) represents the cells treated with $2 \mu \mathrm{M}$ Dox together with $50 \mu \mathrm{M}$ verapamil. The experiments were repeated at least 3 times with similar results, and one representative is shown.

chloroform and then precipitated by ethanol. The extracted DNA was dissolved in Tris-EDTA buffer and subjected to restriction digestion by EcoRI. After overnight digestion, DNA was precipitated and loaded into $1 \% \mathrm{EtBr}$ staining agarose gel for electrophoresis. After that, DNA was transferred to a Nylon membrane (Amersham) and hybridized with 900 bp $m d r 1$ PCR product labeled with ${ }^{32} \mathrm{P}-\mathrm{dCTP}$.

\section{Results}

The expression level of Pgp in cells. By Western blot analysis, the protein level of Pgp in GR, G2R and G10R cells, which are the G, G2 and G10 cells survived after Dox selection respectively, were found to be significantly higher than that of their respective parental cells; G2R > GR > G10R cells (Fig. 2A). By RT-PCR, the $m d r 1$ mRNA level was also highly expressed in GR, G2R and G10R cells; G2R > G10R > GR cells (Fig. 2B). The results suggested that Dox selection induced $m d r l$ overexpression in cells with or without the prior radiation treatment. Overexpression of Pgp in some of the drug-resistant cells is associated with $m d r l$ gene amplification. To investigate whether this is the case in the GR, G2R and G10R cells, Southern blot analysis was performed. All three Dox-selected cells showed $m d r 1$ gene amplification when compared with their respective parental cells and G2R cells showed the highest amplification (Fig. 2C). The fold increases in the $m d r l$ gene copy number in GR, G2R and G10R were $2.87 \pm 0.24,12.80 \pm 0.45$ and $5.49 \pm 0.37$, respectively.

Multidrug resistance characteristics. To study the effect of combination treatment with radiation and anticancer drugs on the drug resistance development in human cancer cells, the drug sensitivity of HepG2 cells and its sublines were examined by MTT assay. GR, G2R and G10R cells were highly resistant to Dox (Fig. 3A), Taxol, vincristine and etoposide (data not shown) when compared with their respective parental cells. 


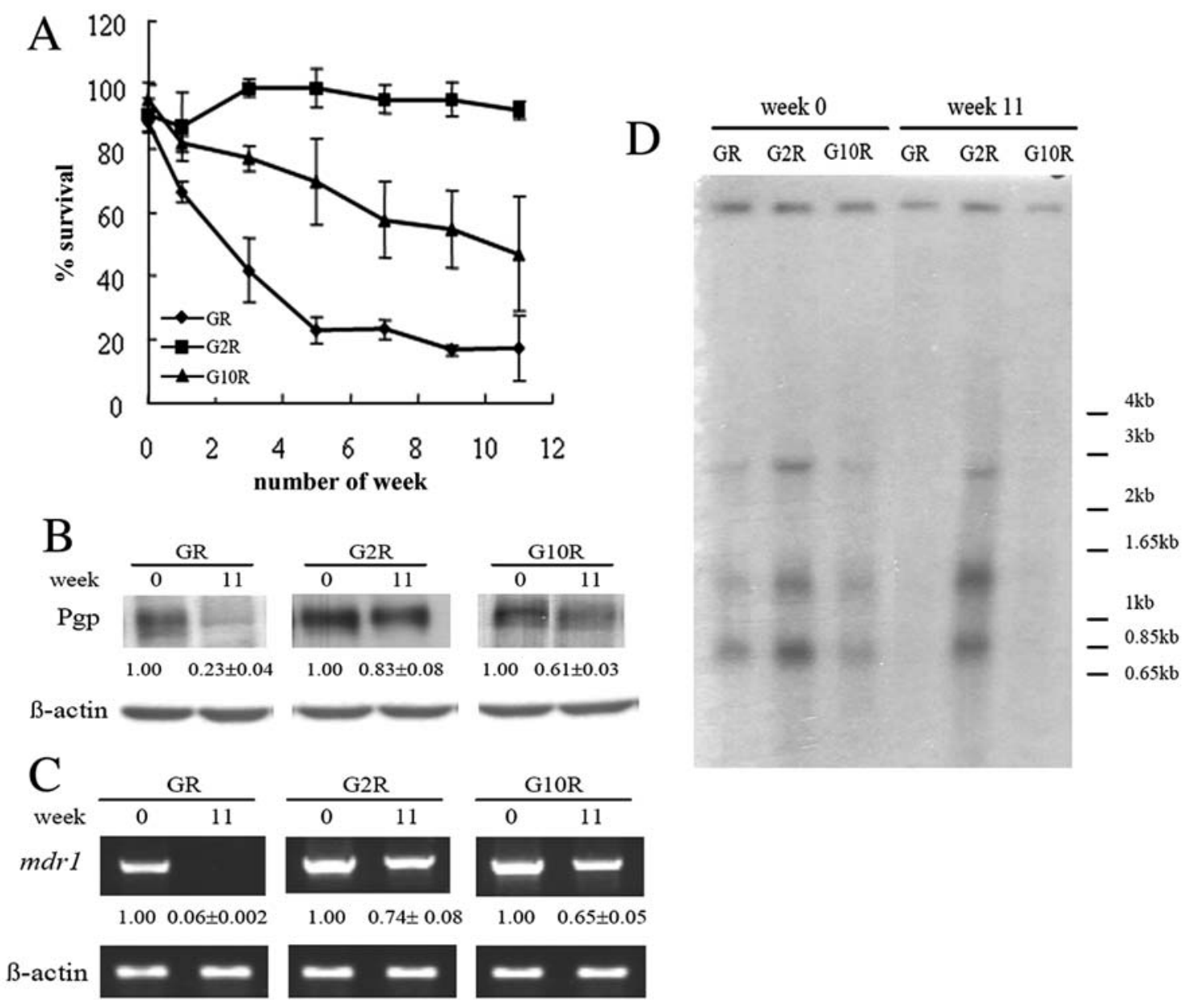

Figure 4. Dox sensitivity, $m d r 1$ expression level and $m d r 1$ gene amplification in GR, G2R and G10R cells culturing in Dox-free medium. GR, G2R and G10R cells were cultured in Dox-free medium for up to 11 weeks. (A) The Dox sensitivity of the GR, G2R and G10R cells was determined by MTT assay in 2-week intervals. ( $\bullet$ Represents GR cells $(\boldsymbol{\bullet})$ represents G2R cells and $(\boldsymbol{\Delta})$ represents G10R cells. Each data point was an average of results obtained from at least three separate experiments. Error bar, standard deviation. The levels of Pgp, $m d r 1$ mRNA, $m d r 1$ gene amplification in cells before culturing in Dox-free medium (week 0) and in Dox-free medium for 11 weeks (week 11) were measured. (B) The Pgp level was determined by Western blot analysis. (C) The $m d r 1$ mRNA level was determined by RT-PCR. (D) The relative $m d r 1$ gene copy number was determined by Southern blot analysis. The experiments were repeated at least 3 times with similar results, and a representative is shown.

Furthermore, by assessing the sensitivity at a higher Dox concentration, G2R cells which have the highest Pgp overexpression are also the most resistant towards Dox $\left(\mathrm{IC}_{50}\right.$ $>10 \mu \mathrm{M})$, followed by $\mathrm{G} 10 \mathrm{R}$ cells $\left(\mathrm{IC}_{50}=3.5 \mu \mathrm{M}\right)$ and $\mathrm{GR}$ cells $\left(\mathrm{IC}_{50}=3.0 \mu \mathrm{M}\right)$. It is therefore indicated that the pattern of drug resistance in the Dox-selected cells is in agreement with their genetic characteristic, $m d r l$ overexpression.

Intracellular Dox accumulation. The major function of Pgp is being a drug efflux pump and thus inducing drug resistance. To further confirm that the drug resistance observed in the Dox- selected cells is associated with Pgp overexpression, the level of intracellular Dox accumulation was determined. As expected, it was shown that GR, G2R and G10R cells have a much lower level of Dox accumulation when compared with their respective parental cells (Fig. 3B).

Verapamil sensitizes Dox-selected cells towards anticancer drugs. The Pgp-associated drug resistance is known to be suppressed by verapamil (6). Therefore, to investigate if the drug resistance in the Dox-selected cells is due to overexpression of Pgp, the effects of verapamil on drug sensitivity and drug accumulation in cells were examined. It was found that verapamil sensitized the Dox response in all HepG2 cells while the sensitization effect is more significant in the GR, G2R and G10R cells (Fig. 3A). In addition, verapamil also increased the intracellular Dox accumulation and the effect was more significant in the GR, G2R and G10R cells (Fig. $3 \mathrm{~B})$. The results from the verapamil study suggest that the drug resistance in the Dox-selected cells is associated with Pgp overexpression.

Decay of Dox resistance property. To maintain the drug resistance in some cell systems, the cells are to be cultured continuously in medium with low concentration of drug. The resistance will decay once the cells are in drug-free medium. To maintain Dox resistance, the Dox-selected HepG2 cells were cultured in medium containing $1.2 \mu \mathrm{M}$ Dox. To investigate if the drug resistance will decay, the cells were in culture without Dox for up to 11 weeks and their Dox sensitivity was determined in 2 -week intervals. The Dox resistance in $\mathrm{G} 2 \mathrm{R}$ cells remained unchanged for up to 11 weeks in Dox-free medium while decayed in GR and G10R cells; GR cells showed greater decay than G10R cells (Fig. 4A). 
However, even in Dox-free medium for 11 weeks, a low level of drug resistance was still maintained in the GR and G10R cells. For GR cells, the percentage survival towards $0.2 \mu \mathrm{M}$ Dox at week 11 was $17 \%$ (Fig. 4A) while it was $6 \%$ for parental G cells (Fig. 3A). For G10R cells, the percentage survival towards $0.2 \mu \mathrm{M}$ Dox was $47 \%$ (Fig. 4A) in comparison with $3 \%$ of parent G10 cells (Fig. 3A). The Pgp protein level decreased by $80 \%$ in GR cells, followed by $40 \%$ in G10R cells while only a slight decrease was seen in G2R cells when cultured in Dox-free condition for 11 weeks (Fig. 4B). A similar decay pattern was seen for the $m d r l$ mRNA level (Fig. 4C). For $m d r 1$ gene amplification, the level of amplification in GR and G10R cells was reduced greatly while there was no significant change in G2R cells (Fig. 4D). The results indicate that the decay in Dox resistance is related to the reduction in Pgp expression in the Dox-selected cells and the process might be regulated at the genomic level.

\section{Discussion}

Radiation treatment in combination with chemotherapy may modify the drug resistance pattern developed in human cancer cells. All the Dox-selected HepG2 cells with or without prior radiation treatment demonstrate the $m d r l$-associated drug resistance as supported by the following: i) Drug-resistant profile. The cells were resistant to Dox (Fig. 3A), Taxol, vincristine and etoposide (data not shown), the substrates of Pgp transporter (4). ii) Overexpression of Pgp/mdrl (Fig. 2). iii) Reduced intracellular Dox accumulation upon Dox treatment (Fig. 3B). iv) Verapamil, a Pgp inhibitor, reversed the resistance towards Dox (Fig. 3A), Taxol (data not shown) and also increased the intracellular Dox accumulation (Fig. 3B). v) The decay of Dox resistance (Fig. 4A) when cells were cultured in Dox-free medium was comparable to the decrease in the levels of Pgp, $m d r l$ mRNA and $m d r l$ gene amplification (Fig. 4B-D). The association of the decay in Dox resistance with the decrease in $m d r l$ gene amplification is compatible with another study in which decrease in $m d r l$ gene copy number was found in the revertant subline of colchicines selected human KB carcinoma cells (15). Even though all the Dox-selected HepG2 cells demonstrate drug resistance property associated with $m d r l$ overexpression, the characteristics of drug resistance is, however, different among the GR, G2R and G10R cells. Among them, G2R cells, which have 2 Gy x 10 days of radiation treatment before the Dox treatment, have significantly higher levels of $m d r l$ overexpression (Fig. 2), drug resistance (Fig. 3) and less resistance decay (Fig. 4A) than that of the GR cells, the cells with Dox treatment only. The results, therefore, indicate that radiation treatment may predispose some kinds of cellular condition(s) that may modify the development of drug resistance profile at the time of chemotherapy in human cancer cells.

Mdrl gene amplification is one of the reasons that leads to $\mathrm{Pgp} / m d r 1$ overexpression in the Dox-selected HepG2 cells. In addition to gene amplification, there are many ways to induce $\mathrm{Pgp} / m d r l$ overexpression in the drug-resistant cells, e.g. transcription activation (16), epigenetic modification of the mdr1 promoter (17), gene rearrangement $(18,19)$, etc. By Southern blot analysis, the $m d r l$ gene in all of the Dox- selected HepG2 cells is markedly amplified when compared with their respective parental cells (Fig. 2C). The increased expression of $m d r 1 / \mathrm{Pgp}$ coupled with the increased $m d r l$ gene copy number has been reported in a number of drugselected cancer cells, including cisplatin-resistant, Taxolresistant ovarian cancer cell lines $(20,21)$ and Dox-resistant breast cancer cell lines (22). Mdrl gene amplification can be due to the amplification of the q21-q22 region of chromosome 7 where the $m d r l$ gene is located or the formation of double minute chromosomes that carry the $m d r l$ gene. Amplification of region on chromosome 7 has been reported in Taxol-selected lung cancer cells (23), vincristine-selected leukemia (24) and Dox-selected prostate carcinoma (25). Amplification associated with double minute chromosome has been found in Dox and vinblastine-resistance KB carcinoma cells (15). The amplification is generally less stable for those associated with double minute chromosome. Decrease in $m d r l$ gene copy number is found in the revertant sublines of several drug-resistant KB carcinoma cell lines $(15,26)$. The decrease in $m d r l$ gene amplification may be due to the loss of double minute chromosomes which contains the $m d r 1$ gene. Although gene amplification may be the cause for Pgp over-expression in the Dox-selected HepG2 cells, the form of $m d r l$ gene amplification in these cells remains to be investigated. However, the form of $m d r l$ gene amplification in G2R cells will likely be different from that in the G10R and GR cells as the $m d r l$ amplification in G2R cells persisted in the absence of Dox while the amplification decayed in G10R cells and even more in GR cells (Fig. 4D). This will only be resolved by molecular cytogenetic analysis of the cells.

In conclusion, results from the present study indicated that radiotherapy followed by chemotherapy will likely modify the drug resistance pattern developed in the surviving cancer cells. The situation is noteworthy as the highest level of $m d r l$ gene amplification, drug resistance and the most stable resistant phenotype is developed in the G2R cells, the cells selected with Dox after they were subjected to fractionated $\gamma$-radiation, a common type of radiotherapy regimen. However, the significance and the impact of the findings will need further validation.

\section{Acknowledgements}

This study was supported by an Earmarked Grant (CUHK4270/ 04M) from Hong Kong Research Grants Council and a grant from the Shanghai-Hong Kong Anson Research Foundation, Hong Kong.

\section{References}

1. Bates SE, Regis JI, Robey RW, Zhan Z, Scala S and Meadows BJ: Chemoresistance in the clinic: Overview 1994. Bull Cancer 81 (Suppl 2): 55-61, 1994.

2. Stavrovskaya AA: Cellular mechanisms of multidrug resistance of tumor cells. Biochemistry (Mosc) 65: 95-106, 2000.

3. Ambudkar SV, Kimchi-Sarfaty C, Sauna ZE and Gottesman MM: P-glycoprotein: From genomics to mechanism. Oncogene 22: 7468-7485, 2003.

4. Gottesman MM, Fojo T and Bates SE: Multidrug resistance in cancer: Role of ATP-dependent transporters. Nat Rev Cancer 2: 48-58, 2002.

5. Mazzanti R, Fantappie O, Fabrizio P, Pacini S, Relli P, Casamassima F, Milano $\mathrm{F}$ and Ruggiero M: Conferring drug resistance by MDR1 gene transfection increases susceptibility to irradiation and lipid peroxidation in $3 \mathrm{~T} 3$ cell line. Free Radic Biol Med 20: 601-606, 1996. 
6. Thomas H and Coley HM: Overcoming multidrug resistance in cancer: An update on the clinical strategy of inhibiting pglycoprotein. Cancer Control 10: 159-165, 2003.

7. David-Beabes GL, Overman MJ, Petrofski JA, Campbell PA, de Marzo AM and Nelson WG: Doxorubicin-resistant variants of human prostate cancer cell lines DU 145, PC-3, PPC-1, and TSU-PR1: Characterization of biochemical determinants of antineoplastic drug sensitivity. Int J Oncol 17: 1077-1086, 2000.

8. Takeda M, Mizokami A, Mamiya K, Li YQ, Zhang J, Keller ET and Namiki M: The establishment of two paclitaxel-resistant prostate cancer cell lines and the mechanisms of paclitaxel resistance with two cell lines. Prostate 67: 955-967, 2007.

9. Kotchetkov R, Cinatl J, Blaheta R, Vogel JU, Karaskova J, Squire J, Hernaiz Driever P, Klingebiel T and Cinatl J Jr: Development of resistance to vincristine and doxorubicin in neuroblastoma alters malignant properties and induces additional karyotype changes: A preclinical model. Int J Cancer 104: 36-43, 2003.

10. Hill BT, Whelan RD, Hosking LK, Bedford P, Dempke WC and Shellard SA: Differential expression of drug resistance following in vitro exposure of human tumour cell lines to fractionated X-irradiation. Cancer Treat Rev 17 (Suppl A): 21-26, 1990.

11. McClean S, Hosking LK and Hill BT: Expression of Pglycoprotein-mediated drug resistance in $\mathrm{CHO}$ cells surviving a single X-ray dose of 30 Gy. Int J Radiat Biol 63: 765-773, 1993.

12. Raitanen M, Rantanen V, Kulmala J, Pulkkinen J, Klemi P, Grenman S and Grenman R: Paclitaxel combined with fractionated radiation in vitro: A study with vulvar squamous cell carcinoma cell lines. Int J Cancer 97: 853-857, 2002.

13. Liebmann J, Cook JA, Fisher J, Teague D and Mitchell JB: In vitro studies of taxol as a radiation sensitizer in human tumor cells. J Natl Cancer Inst 86: 441-446, 1994.

14. ImagelJ US national insititute of health, bethesda, maryland, USA. (homepage on the Internet). Available from: http://rsb.info.nih. gov/ij/, 1997-2007.

15. Shen DW, Fojo A, Chin JE, Roninson IB, Richert N, Pastan I and Gottesman MM: Human multidrug-resistant cell lines: Increased mdr1 expression can precede gene amplification. Science 232: 643-645, 1986.

16. Scotto KW: Transcriptional regulation of $\mathrm{ABC}$ drug transporters. Oncogene 22: 7496-7511, 2003.
17. Chen KG, Wang YC, Schaner ME, Francisco B, Duran GE, Juric D, Huff LM, Padilla-Nash H, Ried T, Fojo T and Sikic BI: Genetic and epigenetic modeling of the origins of multidrugresistant cells in a human sarcoma cell line. Cancer Res 65: 9388-9397, 2005.

18. Huff LM, Lee JS, Robey RW and Fojo T: Characterization of gene rearrangements leading to activation of MDR-1. J Biol Chem 281: 36501-36509, 2006.

19. Mickley LA, Spengler BA, Knutsen TA, Biedler JL and Fojo T: Gene rearrangement: A novel mechanism for MDR-1 gene activation. J Clin Invest 99: 1947-1957, 1997.

20. Takano M, Kudo K, Goto T, Yamamoto K, Kita T and Kikuchi Y: Analyses by comparative genomic hybridization of genes relating with cisplatin-resistance in ovarian cancer. Hum Cell 14: 267-271, 2001.

21. Wang YC, Juric D, Francisco B, Yu RX, Duran GE, Chen GK, Chen X and Sikic BI: Regional activation of chromosomal arm $7 q$ with and without gene amplification in taxane-selected human ovarian cancer cell lines. Genes Chromosomes Cancer 45: 365-374, 2006.

22. Davies R, Budworth J, Riley J, Snowden R, Gescher A and Gant TW: Regulation of P-glycoprotein 1 and 2 gene expression and protein activity in two MCF-7/Dox cell line subclones. Br J Cancer 73: 307-315, 1996.

23. Yabuki N, Sakata K, Yamasaki T, Terashima H, Mio T, Miyazaki Y, Fujii T and Kitada K: Gene amplification and expression in lung cancer cells with acquired paclitaxel resistance. Cancer Genet Cytogenet 173: 1-9, 2007.

24. Carlson KM, Gruber A, Liliemark E, Larsson R and Nordenskjold M: Characterization of drug-resistant cell lines by comparative genomic hybridization. Cancer Genet Cytogenet 111: 32-36, 1999.

25. Zalcberg J, Hu XF, Slater A, Parisot J, El-Osta S, Kantharidis P, Chou ST and Parkin JD: MRP1 not MDR1 gene expression is the predominant mechanism of acquired multidrug resistance in two prostate carcinoma cell lines. Prostate Cancer Prostatic Dis 3: 66-75, 2000

26. Fojo AT, Whang-Peng J, Gottesman MM and Pastan I: Amplification of DNA sequences in human multidrug-resistant KB carcinoma cells. Proc Natl Acad Sci USA 82: 7661-7665, 1985. 